OPEN ACCESS

Edited by:

Hiromitsu Yamagishi,

Hokkaido Research Center of Geology

(HRCG), Japan

Reviewed by:

Yu Huang,

Tongji University, China

Qi Yao,

China Earthquake Networks Center,

China

*Correspondence:

Ji Sen Shu

jsshu888@cumt.edu.cn

Specialty section:

This article was submitted to

Geohazards and Georisks,

a section of the journal

Frontiers in Earth Science

Received: 13 July 2020 Accepted: 16 December 2020

Published: 17 February 2021

Citation:

Tovele GSV, Han L and Shu JS (2021) Variation of Open-Pit Waste Dump

Specimens Under Effective Pressure Influence.

Front. Earth Sci. 8:582918. doi: 10.3389/feart.2020.582918

\section{Variation of Open-Pit Waste Dump Specimens Under Effective Pressure Influence}

\author{
Gerson. S. V. Tovele, Liu Han and Ji Sen Shu* \\ School of Mines, China University of Mining and Technology, Xuzhou, Jiangsu, China
}

The waste dump is a giant artificial loose pile body composed of fine, medium, and coarse particle sizes. Rising incidents of landslides caused by overburden pressure and effective pressure are of increasing concern in the open-pit waste dump and, if not well-controlled, are a dangerous threat to the workers, the environment, and the equipment. The purpose of this research is to investigate the connection between effective pressure, porosity, void ratio, and coefficient of permeability and to find their influence in the open-pit waste dump. This study analyzed the mechanical and physical changes of seven different soil samples using consolidation and permeability under consolidation laboratory test. The test samples were subject to a pressure ranging from 100 to $1600 \mathrm{kPa}$. The effective pressure was found to play a major role in influencing void ratio, porosity, and coefficient of permeability, and waste dump height management and control are of great importance. This study answers the question regarding the correlation between effective pressure, void ratio, porosity, and coefficient of permeability in the open-pit waste dump. Further studies are needed to establish profound relationships and develop preventative measures to keep the waste dump slope stable and safe.

Keywords: waste dump, effective pressure, coefficient of permeability, porosity, void ratio

\section{INTRODUCTION}

The extraction of mineral materials brings many indispensable benefits to humans such as rapid economic growth, production of new intelligent technologies (for factories, hospitals, construction, and others), but also brings environmental problems such as landslide in the waste dump of the open-pit mine. The importance of investigating dangerous hazards that contribute to landslides is urgent. The increase in extraction and production of minerals will consequently increase waste overburden. Therefore, waste dump needs to have good overburden management and more investigations about dangerous hazards influencing landslide for a better and safe waste dump environment should be conducted (Kainthola et al., 2011; Verma et al., 2013; Han et al., 2015; Das and Sobhan, 2016; Sharma et al., 2017; Bao et al., 2019).

Water is commonly known as one of the major triggers for landslide failures; according to statistics, over $90 \%$ of landslide failures were related to water (Liu and Li, 2015). During rainfall, as water infiltrates into the slope, the pore water pressure increases (Zhou et al., 2013; Cheng et al., 2014; Gui and Wu, 2014; Damiano et al., 2017; Chen et al., 2018), reducing the shear resistance of saturated soil, leading to rapid, long-travel landslide moments (Guan et al., 2010; Zhang et al., 2013; Tavakoli Dastjerdi et al., 2014; Wen and Yan, 2014; Zhang et al., 2017; Hou et al., 2018). The waste dump is susceptible to geological disasters due to loosening of packing 
(Shakesby and Whitlow, 1991; Bao et al., 2019) and the different soil sizes packing. In this study, we will be more focused on effective pressures influencing the porosity, void ratio, and permeability of water in the soil. Researchers have investigated infiltration of water in compacted soils (Oh and Vanapalli, 2010; Mohammadshirazi et al., 2017; Chen et al., 2019a). Chen et al. (2020) analyzed shear deformation and failure of unsaturated sandy soils in surface layers of slopes during rainwater infiltration, found a unique relationship between the deformation and moisture content, and suggested a relationship for predicting the time and moisture content of onset of landslides. Rosli et al. (2019) studied shear strength and permeability properties of lateritic soils from North West Malaysia due to extended compaction and, as a result, found that the increased compaction brought significant enhancement to the shear strengths. Kim et al. (2018) presented the development of a numerical model for simulating a triaxial shearing-infiltration test to investigate the shear strength characteristics of compacted kaolin under infiltration conditions. Tan and Chen (2016) analyzed the physicochemical characteristics of cohesive sediments and the consolidation mechanism to develop a dynamic model and status formula for the density during the initial stage of consolidation. Chen et al. (2019b) used the Chang 101 member of the Yanchang formation as the study object and aimed to improve the understanding of the controlling factors in relatively high permeability zones in low permeability sandstone reservoirs. Rahmouni et al. (2013) studied the permeability and porosity of rocks and their relationship based on laboratory measurements. Rahmouni et al. (2014) studied relationships between porosity and the permeability of calcarenite rocks based on laboratory measurements and, as a result, found that permeability and porosity are closely related to each other in a very good direct proportional relationship.

The present article analyzes the permeability characteristics of different waste dump composition under effective stress conditions. The major objectives of this research are as follows:

(1) To study and understand the mechanical and physical changes in different-sized specimens under different effective pressures. The article identifies different reactions for different specimen sizes and mixtures when applied to effective pressure.

(2) To analyze the permeability of water in waste dump soils under effective pressure.

(3) To obtain the relationship between the coefficient of permeability, void ratio, porosity, and effective pressure.

To the best of the author's knowledge, the variation of openpit waste dump specimens under effective pressure influence has not yet been fully examined. Therefore, to achieve the objectives of the present article, consolidation tests and permeability under consolidation tests are performed. The experimental program, test result, and discussion are described in the following sections.

\section{EXPERIMENTAL PROGRAMS}

\section{Material}

The soil samples used in this experience were chosen according to the three particle sizes: clay, sand, and sandstone. Figure 1 shows the three different specimens used in this experience.

The waste dump is a giant artificial loose pile body of fine, medium, and coarse particle sizes. The waste dump is composed of slope and layer with different soil particle percentages; in the present article, tests of different soil compositions were carried out for the following specimens: $1: 1: 1,1: 2: 4,1: 4: 2$, and 4:2:1 (clay: sand: sandstone). The proportions of the mixed materials are considered according to the geological profiles and weight-volume relationship of different mines such as 1:2:4 (Hequ open-pit mine), 1:4:2 (Shenhuabao rixile open-pit mine and Yiminhe open-pit mine), 4:1:2 (Xiaolongtan open-pit mine), and 1:1:1 for comparison of different specimens with the same percentage. Table 1 shows the machine description of the equipment; Table 2 shows the index properties of the specimens used in the consolidation and permeability test.

\section{Consolidation Test}

Consolidation test apparatus was set up to test porosity and void ratio in open-pit waste dump soils (clay, sand, and sandstone, $1: 1: 1, \quad 1: 2: 4, \quad 1: 4: 2$, and $4: 1: 2)$. The onedimensional consolidation testing procedure was first suggested by Terzaghi. The test is performed in a consolidometer (sometimes referred to as an oedometer); the schematic diagram of a consolidometer is shown in Figure 2. The soil specimen is placed inside a metal ring with two porous stones and wet filter paper, one at the top and another at the bottom of the specimen. The soil specimens of $61.8 \mathrm{~mm}$ in diameter and $40 \mathrm{~mm}$ in height were prepared; for each type of specimen, four laboratory tests were conducted, and the results were obtained according to the average of each type of soil specimen. The specimen is kept underwater during the test; each load is kept for $24 \mathrm{~h}$. After that, the load is doubled, which doubles the pressure on the specimen, and the compression measurement is continued. The loading sequence of stages selected from the following range of pressures is considered appropriate: $100,200,400,800$, and $1600 \mathrm{kPa}$. At the end of the test, the dry weight of the test specimen is determined. Figure $2 \mathrm{~A}$ shows a consolidation test in progress.

\section{Experimental Principle (Method)}

After the time-deformation plots for various loadings are obtained in the laboratory, it is necessary to study the change in the void ratio and porosity of the specimen with pressure, firstly calculating $H_{s}$ and $H_{v}$ to obtain $e_{0}$ : 


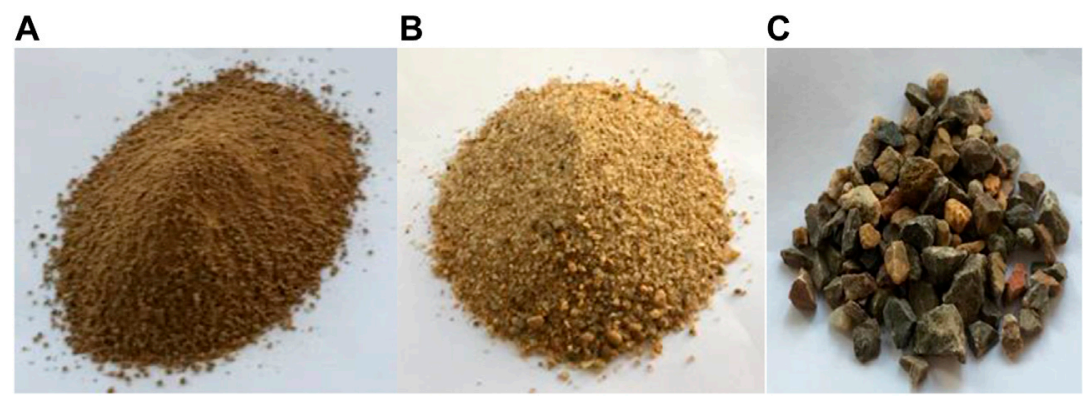

FIGURE 1 | Specimens used in the experience. (A) Fine specimen (clay); (B) medium specimen (sand); (C) coarse specimen (sandstone).

TABLE 1 | Machine description.

TABLE 2 | Index properties of the laboratory tests.

\begin{tabular}{|c|c|c|c|c|c|c|}
\hline Specimen name & $\begin{array}{l}\text { Diameter } \phi \\
(\mathbf{m m})\end{array}$ & $\begin{array}{c}\text { Specific gravity } \\
\qquad G_{s}\end{array}$ & $\begin{array}{c}\text { Moisture content } \\
(\%)\end{array}$ & $\begin{array}{l}\text { Dry density } \\
\left(\times 10^{3} \mathrm{~kg} / \mathrm{m}^{3}\right)\end{array}$ & Cohesion (kPa) & $\begin{array}{c}\text { Internal friction } \\
\text { angle }\left({ }^{\circ}\right)\end{array}$ \\
\hline Fine (clay) & $0.25-0.50$ & 2.53 & 36.56 & 1.31 & 38.3 & 28.5 \\
\hline Medium (sand) & $0.8-2.0$ & 2.69 & 30.6 & 1.48 & 1.65 & 33.15 \\
\hline Coarse (sandstone) & $5.0-8.0$ & 2.41 & 5.5 & 1.39 & 0 & 36 \\
\hline $1: 1: 1$ & - & 2.54 & 14.57 & 1.85 & - & - \\
\hline $1: 2: 4$ & - & 2.51 & 17.93 & 1.73 & - & - \\
\hline $1: 4: 2$ & - & 2.59 & 14.67 & 1.88 & - & - \\
\hline $4: 1: 2$ & - & 2.52 & 21.03 & 1.65 & - & - \\
\hline
\end{tabular}

$$
\begin{gathered}
H_{S}=\frac{m_{s}}{A G_{s \rho_{w}}}, \\
H_{v}=H-H_{s} .
\end{gathered}
$$

After calculating Eqs 1 and 2, it is possible to obtain the following:

$$
e_{0}=\frac{V_{v}}{V_{s}}=\frac{H_{V} A}{H_{S} A}=\frac{H_{v}}{H_{s}},
$$

where $e_{0}$ is the initial void ratio; $V_{v}$ is the void volume; $V_{s}$ is the soil volume; $H$ is the initial height of specimen; $H_{v}$ is the height of the voids; $H_{s}$ is the final height of specimen; $m_{s}$ is the final weight of soil specimen; $A$ is the specimen area.

For the $1^{\text {st }}$ loading, change in void ratio due to $1^{\text {st }}$ loading $\left(\Delta \mathrm{e}_{1}\right)$ is as follows:

$$
\Delta e_{1}=\frac{\Delta H_{1}}{H_{s}}
$$

New void ratio after the $1^{\text {st }}$ loading $\left(\Delta e_{1}\right)$ is as follows:

$$
e_{1}=e_{0}-\Delta e_{1} \text {. }
$$

For the $2^{\text {nd }}$ loading, change in void ratio due to $2^{\text {nd }}$ loading $\left(\Delta e_{2}\right)$ is as follows:

$$
\Delta e_{2}=\frac{\Delta H_{2}}{H_{s}} .
$$

New void ratio after the $2^{\text {nd }}$ loading $\left(\Delta e_{2}\right)$ is as follows:

$$
e_{2}=e_{1}-\frac{\Delta H_{2}}{H_{s}}
$$

$\Delta H_{1}$ is obtained from the initial and the final dial readings for the loading. This is the process to obtain void ratio under different effective pressures (Das and Sobhan, 2016).

$$
n=\frac{V_{v}}{V} \times 100 \%=\frac{H_{v} A}{H A}=\frac{H_{v}}{H} \times 100 \%,
$$

where $n$ is porosity; $V_{v}$ is pore volume; $V$ is total soil volume.

\section{Permeability of Soil Test}

A soil specimen under effective pressure is considered, which means using loads to consolidate the soils, causing the soil to pack together more tightly. Then, a permeability test is applied to verify seepage laws in the specimen under effective pressure. The same loading sequences of stages as in the consolidation test are selected: $100,200,400,800$, and $1,600 \mathrm{kPa}$. For fine, 1:1:1, and 4:1:2 specimens, each increment of loading must be held constant 

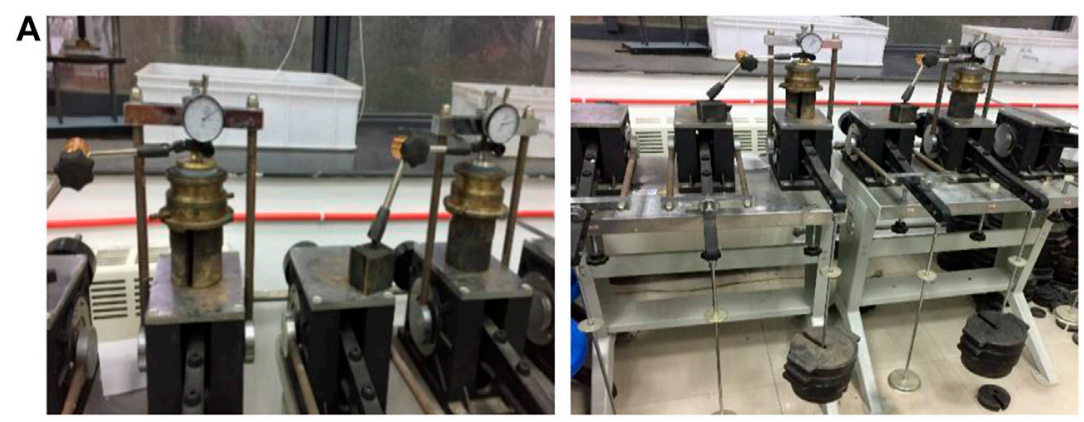

B

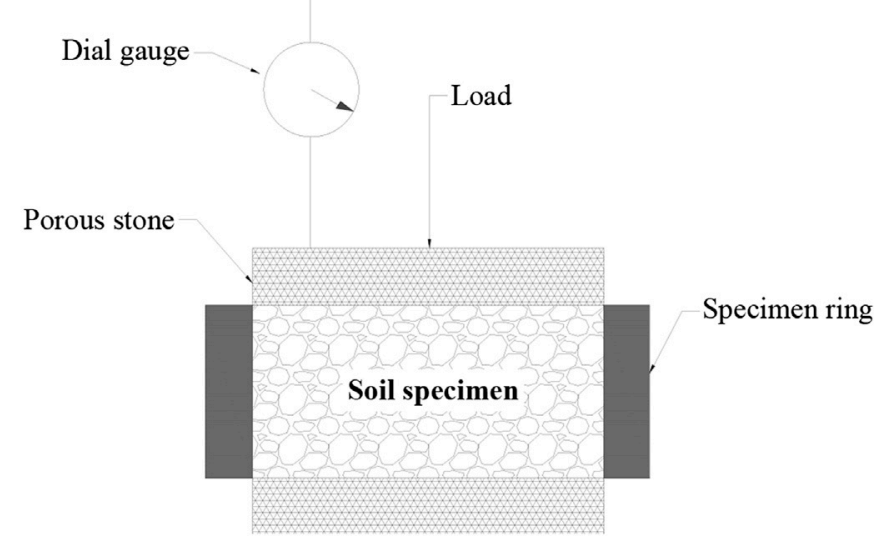

FIGURE 2 | Loading device. (A) Laboratory loading device and consolidation test in progress; (B) schematic diagram of a consolidometer.

for $24 \mathrm{~h}$. However, for medium, coarse, 1:4:2, and 1:2:4 specimens, each increment of loading was held constant for $4 \mathrm{~h}$. Taking into account the fact that the laboratory test made is a permeability test of soils under consolidation and that the variation of coefficient of permeability $(k)$ depends on the variation of void ratio $(e)$, it was possible to notice that for the case of medium, coarse, 1:4:2, and 1:2:4 specimens, when applying the effective pressure, its variations were greater in the first $4 \mathrm{~h}$; that is, for each load given in $24 \mathrm{~h}$, the variation occurred in the initial $4 \mathrm{~h}$. From the fourth to the twenty-fourth hour, the variation was almost equal to or equal to zero. Therefore, it is possible to conclude that for these specimens, it is acceptable to apply the consolidation test for each load in the initial $4 \mathrm{~h}$. In this case, different consolidation time will not affect the experimental result.

\section{Experimental Principle (Method)}

To understand the seepage movements considering effective pressure action, the coefficient of permeability used the constant-head and falling-head tests.

\section{Constant-Head Test}

It is performed in high permeability specimen $k>10^{-04}$ (medium, coarse, and 1:2:4). The water supply at the inlet and outlet remains constant during the test period. After a constant flow rate is established, water is collected in a graduate flash for a known duration, as shown in Figure 3:
The constant-head coefficient of the permeability test formula is as follows:

$$
k=\frac{Q L}{A t h}
$$

\section{Falling-Head Permeability Test}

It is performed in low permeability specimen $k<10^{-04}$ (fine, 1:1: $1,1: 4: 2$, and 4:1:2). The initial head difference $\mathrm{h}_{1}$ at time $t=0$ is recorded, and water is allowed to flow through the soil specimen such that the initial head difference at time $t=\mathrm{t}_{2}$ is $\mathrm{h}_{2}$, as shown in Figure 4.

The falling-head coefficient of the permeability test formula is as follows:

$$
k=2.303 \frac{a L}{A t} \log _{10} \frac{h_{1}}{h_{2}} .
$$

\section{RESULTS}

\section{Consolidation Test Result}

Specimen Height Deformation (Dial Reading) vs. Time and Effective Pressure

When applying effective pressure in fine and 4:1:2 specimens, elastic settlement occurs immediately. The same happens with 1: $1: 1$ when $100 \mathrm{kPa}$ load is applied, and with the increase of 

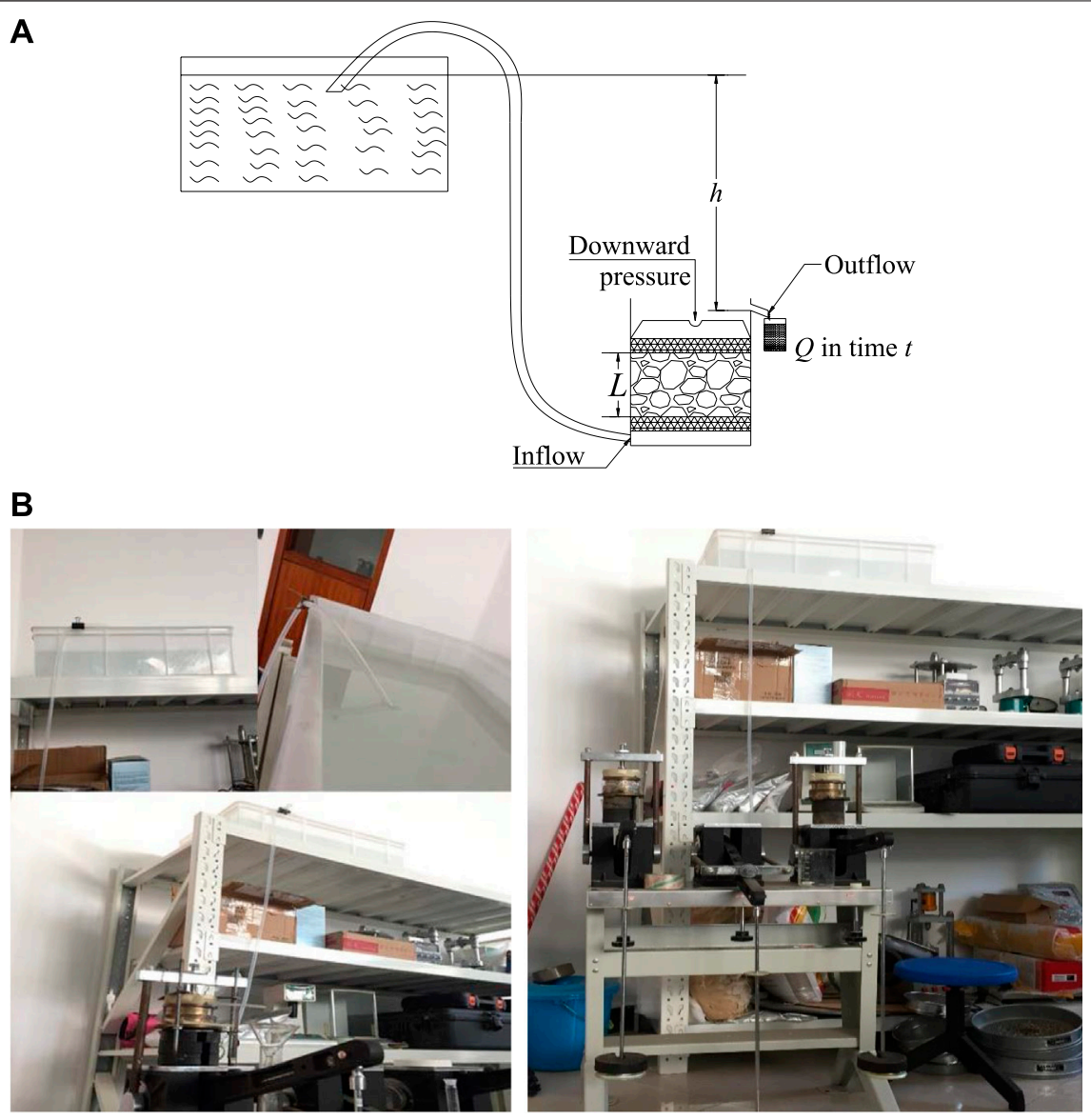

FIGURE 3 | Constant-head permeability test. (A) Schematic diagram of constant-head permeability test under effective pressure; (B) laboratory constant-head permeability test under effective stress in progress.

pressure, the presence of medium and coarse specimens is more notable.

The elastic settlement and consolidation of the medium specimen occur simultaneously. The same happens with 1:4:2; however, when $100 \mathrm{kPa}$ load is applied, the variation of 1:4:2 is bigger than that of the medium specimen.

When the coarse and 1:2:4 specimens were subjected to stress increase, the elastic settlement did not occur immediately. However, the bigger the effective pressure is, the bigger the elastic settlement will be. According to the analyses, it is possible to conclude that the bigger the effective pressure applied in the coarse specimen, the bigger the deformation. The relationship between dial reading vs. time and effective pressure is given in Figure 5.

\section{Void Ratio and Porosity vs. Effective Pressure}

The relationship between void ratio, porosity, and effective pressure is given in Figure 6. When the fine specimen is under pressure, the void ratio and porosity variation decrease dramatically, and the same happens with the 4:1:2 specimens.

In the initial load $(100 \mathrm{kPa})$, the $1: 1: 1$ specimen variation decreases dramatically, although, in $200-1,600 \mathrm{kPa}$, the specimen variation becomes slow. The coarse and 1:2:4 specimen variations are similar, and the pressure given to the specimens makes sandstone break into small pieces and occupies the voids between them, making porosity and void ratio smaller. Medium and 1:4:2 specimens both decrease with the increase of effective pressure and have similar variations. However, when comparing the medium specimen with fine and coarse specimens, the medium specimen decreases slowly. According to the results obtained, it is possible to conclude that void ratio and porosity decrease with the increase of effective pressure (see Figure 6).

\section{Permeability of Soil Test}

\section{Coefficient of Permeability vs. Effective Pressure}

The relationship between the coefficient of permeability $(k)$ and effective pressure is given in Figure 7. During the experience, it was possible to analyze the influence that the effective pressure has on the variation of coefficient of permeability in the soil.

The $k$ variations of fine and 4:1:2 specimens are similar. Both are mostly composed of clay, and clay is a low permeable soil that when the load is applied, it becomes more difficult for the water to seep in. 


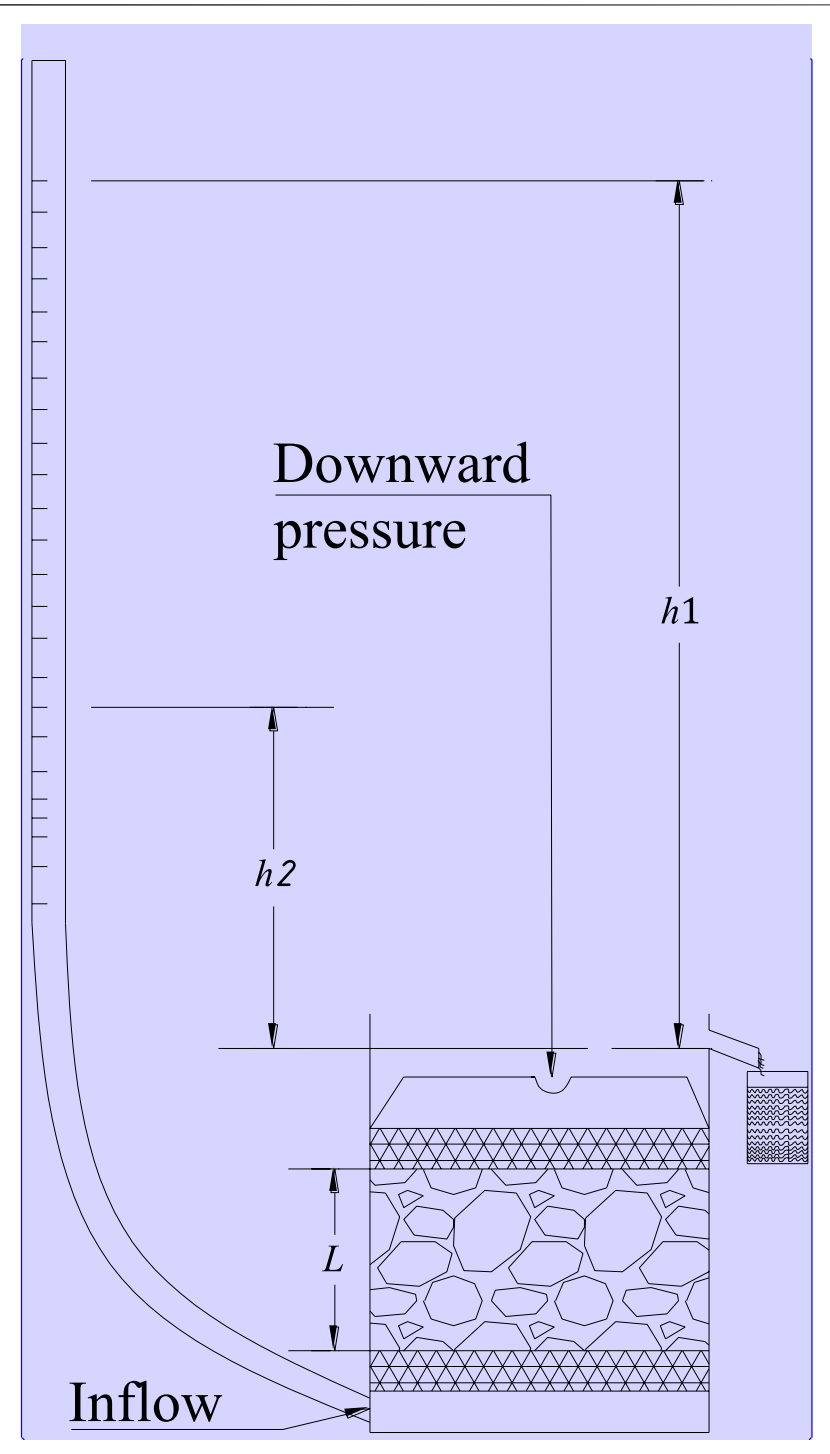

FIGURE 4 | Falling-head permeability test.

For $1: 1: 1$, the difference between $k$ when effective pressure is 100 and $1600 \mathrm{kPa}$ is big, and the fine specimen is the soil with the biggest influence.

Sandy soils (medium specimen) are highly permeable soils; the drainage caused by the increase in the pore water is immediate. When the effective pressure is increased, $k$ will decrease; but the variation is not so big as that in a fine specimen. Even though sandy soil had the biggest percentage in 1:4:2, with the increase of effective pressure, $k$ had big variation because of the presence of fine specimen.

Coarse specimens are highly permeable soils, and the drainage caused by the increase in the pore water is completed immediately. The increase in pressure leads to a decrease in $k$, but the variation is very insignificant. The 1:2:4 specimens are highly permeable because they majorly consisted of coarse soil; however, because of the presence of fine and medium specimen, there is a decrease of $k$ when effective pressure is added.

\section{DISCUSSION}

In this study, the consolidation and permeability under consolidation tests are applied. To better understand the relationship between void ratio, porosity, coefficient of permeability, and effective pressure in a waste dump, different soil specimens are analyzed. The test results show that porosity, void ratio, and coefficient of permeability $(k)$ decrease with the increase of effective pressure, and different soil specimens have different variations.

Rosli et al. (2019) presented properties associated with shear strength and permeability of three lateritic soil samples (LS1, LS2, and LS3) from Malaysia's local sources. The results showed that the coefficient of permeability $(k)$ generally decreases with increasing compaction energy applied for all the samples. And the same applies to the present article. According to Rosli et al. (2019) LS1, LS2, and LS3 did not indicate a significant difference in $k$ reduction between soils, which means any effort spent to reduce $k$ through increased compaction would be futile probably due to structural limitations within the specimen. The present article obtained a different result, an increase in the effective pressure $(100 \mathrm{kPa}$ increased to $1600 \mathrm{kPa})$; the coefficient of permeability generally decreases (Figure 7). Medium specimen's $k$ variation was the lowest in the permeability under consolidation test; this is due to the presence of detrital quartz in sand known for its strong compaction resistance, which is beneficial to the pore preservation of medium specimen during consolidation. After receiving the effective pressure, the coarse and 1:2:4 specimens proved to be very highly permeable specimens, indicating that both have high porosity. The $k$ variations of the medium, coarse, and 1:2:4 specimens are not large. However, the $k$ variation for fine, $1: 1: 1,1: 4: 2$, and $4: 1: 2$ specimens is very notable, especially for $1: 1: 1$ and $1: 4: 2$ specimens (see Figure 7). In 1:1:1 and 1:4:2 specimens, the quantity of high permeable soils (medium + coarse $\geq 2 / 3$ ) is greater than the low permeable soils (fine $\leq 1 / 3$ ); however, the coefficient of permeability is very low, leading the present article to agree with Rahmouni et al. (2013) and Rosli et al. (2019). Rahmouni et al. (2013) concluded that the amount of clayey components influences the permeability of porous material. Rosli et al. (2019) concluded that the permeability of soil might be dictated by the clay content regardless of being minor. Besides, according to the present article, tests were able to find that the settlement caused by consolidation in clay may be several times greater than the elastic settlement.

Chen et al. (2019a) took reservoir sandstones of the Shanbei area in the Ordos Basin as an example. The results showed that the reduction of the intergranular volume caused by the compaction is $40-70 \%$ and that compaction is the dominant control on porosity loss. The present article agrees with Chen et al. (2019b). Besides, this study conducted tests to analyze the behavior of void ratio and porosity of soils under effective pressure. The results showed that when effective pressure is applied, fine, medium, coarse, 1:1:1, 1:2:4, 1:4:2, and 4:1:2 specimens' porosity and void ratio decrease (see Figure 6). Therefore, it is possible to conclude that with an increase in effective pressure, both soil's void ratio and porosity will decrease. 

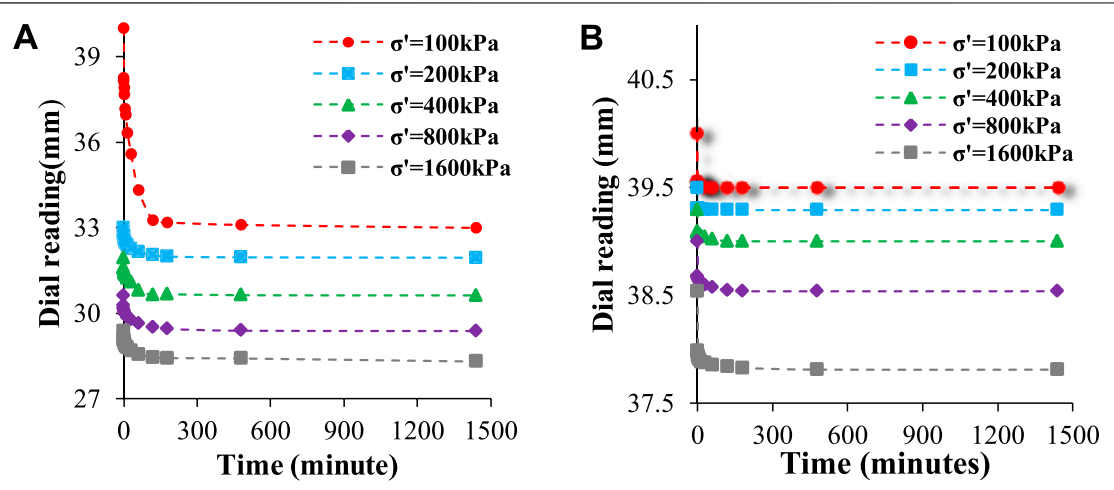

C

D
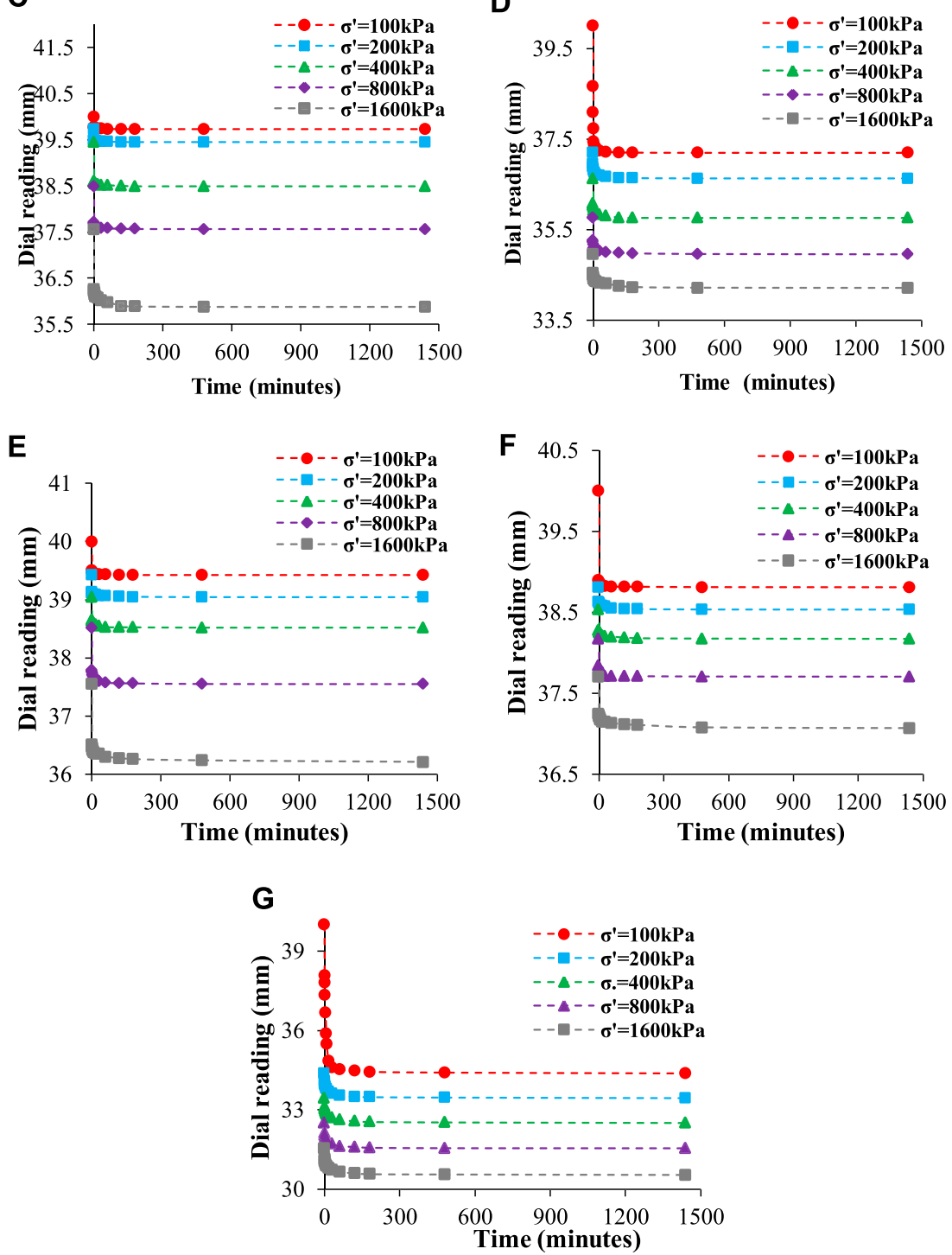

FIGURE 5|Dial reading-time during consolidation for load increment. (A) Fine specimen; (B) medium specimen; (C) coarse specimen; (D) 1:1:1 specimen; (E) 1:2: 4 specimen; (F) 1:4:2 specimen; (G) 4:1:2 specimen. 

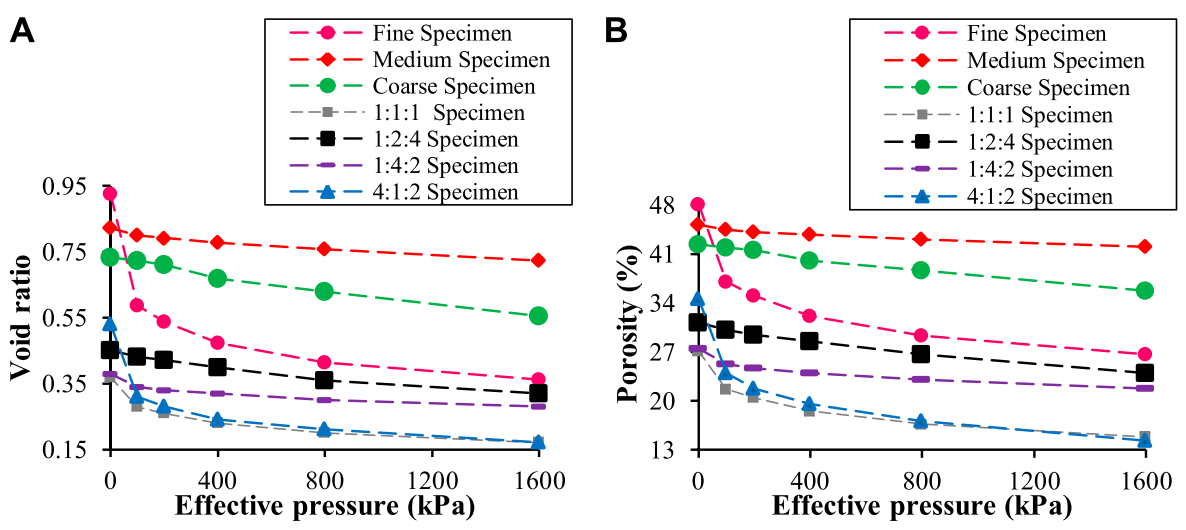

FIGURE 6 | Void ratio and porosity relationship with effective pressure. (A) Void ratio vs. effective pressure; (B) porosity vs. effective pressure.

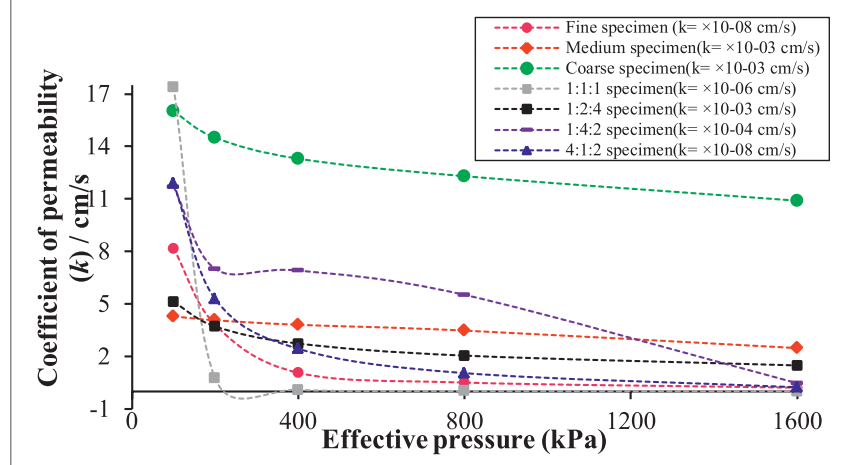

FIGURE 7 | Coefficient of permeability and effective pressure relationship.

Chen et al. (2019a) concluded that the grain size positively influences the reservoir quality and that the coarser the grain, the greater the porosity and permeability values. The present article agrees and disagrees with these conclusions. The reason for agreeing is that the soil specimen used by Chen et al. (2019b) had the content of detrital quartz known for its high maturity and strong compaction resistance, and the reason for disagreeing is that not all coarse grains have strong compaction resistance; in the present article, it was possible to analyze the reaction of coarse specimens breaking during consolidation tests (see Figure 8).

As can be seen in Figure 8, after the consolidation test, small grains are created by breakage, after the same grains intercalated and blocked the existent pores, influencing the porosity, void ratio, and coefficient of permeability. According to the present results, a coarse specimen diagram was created (see Figure 9).

From Figure 9 diagram, it is possible to understand the following points:

(1) The stronger the compaction resistance the coarse grains have, the greater the porosity, void ratio, and permeability values.
(2) The weaker the compaction resistance the coarse grains have, the smaller the porosity, void ratio, and permeability values.

The present article also studies the porosity, void ratio, and coefficient of permeability relationship by combining Figures 5-7. It was possible to compare porosity, void ratio, and $k$ when effective pressure is $1600 \mathrm{kPa}$ (last load) and $\Delta$ variation of effective pressure is from 0 to $1600 \mathrm{kPa}$. This comparison obtained the following results:

(1) Comparison of void ratio, porosity, and coefficient of permeability when effective pressure $=1,600 \mathrm{kPa}$ :

Porosity: medium $>$ coarse $>$ fine $>1: 2: 4>1: 4: 2>1: 1: 1>4: 1: 2$.

Void ratio: medium $>$ coarse $>$ fine $>1: 2: 4>1: 4: 2>1: 1: 1>4: 1: 2$.

Coefficient of permeability: coarse $>$ medium $>1: 2: 4>1: 4: 2>$ 1:1:1 > 4:1:2 > fine.

(2) Comparison of void ratio, porosity, and coefficient of permeability variation $(\Delta)$ from 0 to $1,600 \mathrm{kPa}$ (void ratio and porosity biggest changes):

Porosity: fine $>$ 4:1:2 $>1: 1: 1>$ coarse $>1: 2: 4>1: 4: 2>$ medium.

Void ratio: fine $>4: 1: 2>1: 1: 1>$ coarse $>1: 2: 4>1: 4: 2>$ medium.

Coefficient of permeability: 1:1:1 $>4: 1: 2>1: 4: 2>$ fine $>$ coarse $>1: 2: 4>$ medium.

According to Das and Sobhan (2016) soils are permeable due to the existence of interconnected voids through which water can flow from high energy points to low energy points. The present article agrees with Das and Sobhan (2016). However, comparing porosity, void ratio, and coefficient of permeability $(k)$ in (1), it is possible to analyze that when the effective pressure is $1600 \mathrm{kPa}$, the coarse specimen has the best $k$, the second-best void ratio, and the second-best porosity. Although the fine specimen has a better void ratio and porosity than 1:2:4, 1:4:2, 1:1:1, and 4:1:2, at the same time, the fine specimen has lower permeability than all others. 

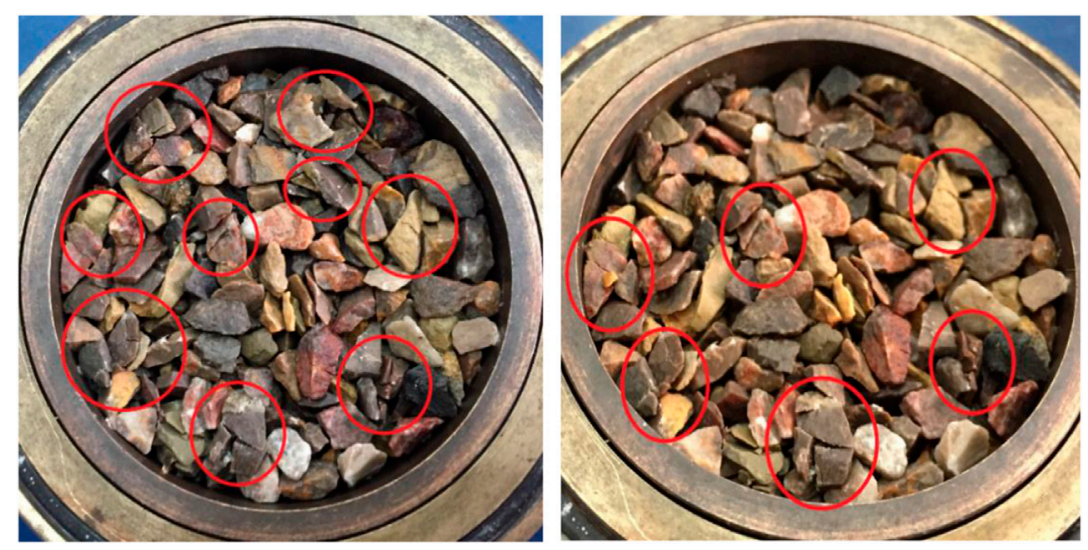

FIGURE 8 | Coarse specimen reacting to effective pressure.

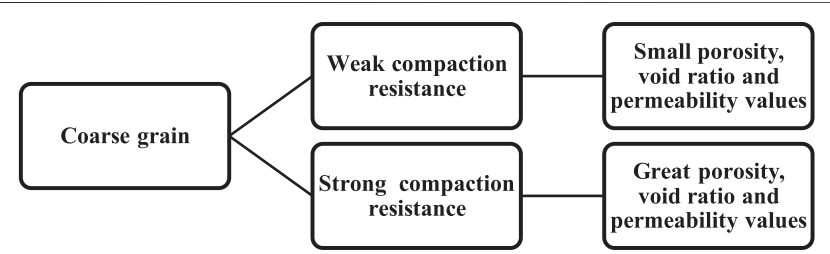

FIGURE 9 | Relationship between coarse grain, porosity, void ratio, and permeability diagram.

When effective pressure on the coarse specimen is applied, there is contact between grains resulting in volume reduction due to breakage and intercalation. From a calculation point of view, the present article found that when effective pressure is applied, the coarse specimen has low porosity, low void ratio, and a high coefficient of permeability. However, from a real point of view, it has a high void ratio, porosity, and coefficient of permeability.

The coarse specimen presented in this article is highly porous (Figure 1C and Figure 10A), and with an increase in pressure, it will slightly decrease. However, the porosity will continue to be
A

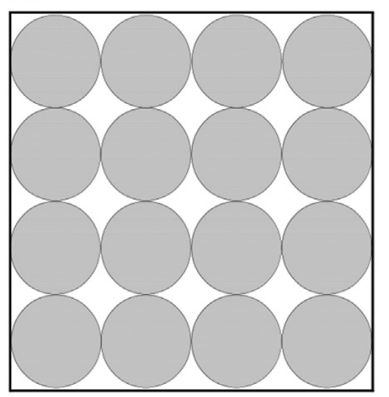

B

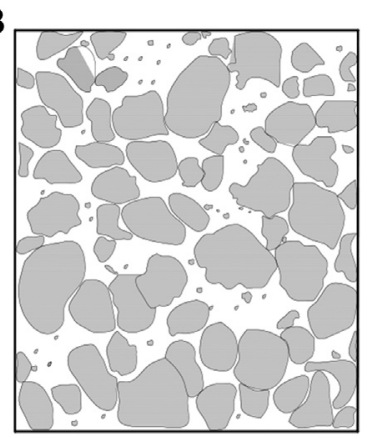

FIGURE 10 | Coarse specimen stages during consolidation test. (A) Coarse specimen before consolidation; (B) coarse specimen after consolidation.

high, as shown in Figure 10B. In the case of 1:2:4, 1:4:2, 1:1:1, and 4:1:2 specimens, specimens that contain an amount of coarse grain will have a reaction on them. Therefore, the present article agrees with Rahmouni et al. (2014) that permeability and porosity

TABLE 3 | Relationship results of the experimental tests.

\begin{tabular}{|c|c|c|c|c|c|}
\hline Specimen & Dump height & Effective pressure & Void ratio & Porosity & $\begin{array}{l}\text { Coefficient of } \\
\text { permeability }\end{array}$ \\
\hline \multirow[t]{2}{*}{ Fine } & $\uparrow$ & $\uparrow$ & $\downarrow$ & $\downarrow$ & $\downarrow$ \\
\hline & $\downarrow$ & $\downarrow$ & $\uparrow$ & $\uparrow$ & $\uparrow$ \\
\hline \multirow[t]{2}{*}{ Medium } & $\uparrow$ & $\uparrow$ & $\downarrow$ & $\downarrow$ & $\downarrow$ \\
\hline & $\downarrow$ & $\downarrow$ & $\uparrow$ & $\uparrow$ & $\uparrow$ \\
\hline \multirow[t]{2}{*}{ Coarse } & $\uparrow$ & $\uparrow$ & $\downarrow$ & $\downarrow$ & $\downarrow$ \\
\hline & $\downarrow$ & $\downarrow$ & $\uparrow$ & $\uparrow$ & $\uparrow$ \\
\hline \multirow[t]{2}{*}{$1: 1: 1$} & $\uparrow$ & $\uparrow$ & $\downarrow$ & $\downarrow$ & $\downarrow$ \\
\hline & $\downarrow$ & $\downarrow$ & $\uparrow$ & $\uparrow$ & $\uparrow$ \\
\hline \multirow[t]{2}{*}{$1: 2: 4$} & $\uparrow$ & $\uparrow$ & $\downarrow$ & $\downarrow$ & $\downarrow$ \\
\hline & $\downarrow$ & $\downarrow$ & $\uparrow$ & $\uparrow$ & $\uparrow$ \\
\hline \multirow[t]{2}{*}{$1: 4: 2$} & $\uparrow$ & $\uparrow$ & $\downarrow$ & $\downarrow$ & $\downarrow$ \\
\hline & $\downarrow$ & $\downarrow$ & $\uparrow$ & $\uparrow$ & $\uparrow$ \\
\hline \multirow[t]{2}{*}{$4: 1: 2$} & $\uparrow$ & $\uparrow$ & $\downarrow$ & $\downarrow$ & $\downarrow$ \\
\hline & $\downarrow$ & $\downarrow$ & $\uparrow$ & $\uparrow$ & $\uparrow$ \\
\hline
\end{tabular}


are in a close relationship, depending on the amount of void space in the tested material.

The present article used sandy soils for testing, and the same happened with Chen et al. (2020). Sandy soils are highly permeable and compaction resistance soils. Chen et al. (2020) test conditions $(8.4-13.2 \mathrm{kPa})$ did not have enough pressure to influence the water intensity in sandy soil. On the other hand, the present article used $100,200,400,800$, and $1600 \mathrm{kPa}$ of effective pressure to analyze $k$ variation. And the result shows that the medium specimen (sandy soil) is stronger in consolidation and is high in permeability. However, under these load conditions, there was a decrease in variation of $k$, indicating that effective pressure influences the coefficient of permeability of the medium specimen.

Kainthola et al. (2011) found that effective shear stress has increased with a rise in the dump. Based on Kainthola et al. (2011) discovery, the present article adds that the rise in the dump slope will lead to an increase in overburden pressure, effective pressure, and effective shear stress. Han et al. (2015) found that stability factor (Fs) decreased rapidly with the increase in dump height $\mathrm{H}$. The relevant results found by the present article lead to the conclusion that the increase in height will give more effective overburden pressure to the dump and water will take a longer time to flow throughout the dump slope; consequently, the weight will increase and friction will decrease, resulting in a landslide (Table 3).

\section{CONCLUSION}

In the present study, seven kinds of specimens with different soil particle percentages and characteristics were tested by consolidation and permeability of soil laboratory tests. The laboratory tests were used to determine and reveal the change rule of the coefficient of permeability, void ratio, and porosity under effective pressure and to analyze the coupling relationship between the coefficient of permeability, void ratio, porosity, and effective pressure, revealing the effect of these factors on waste dump deformation, changes, and safety. Based on the findings, the present article can help prevent future waste dump accidents and present a better working environment in the open-pit waste dump. The specific conclusions are as follows:

(1) The increase in waste dump height increases the effective pressure. The increase in height gives more effective overburden pressure to the waste dump. Consequently,

\section{REFERENCES}

Bao, Y., Han, X., Chen, J., Zhang, W., Zhan, J., Sun, X., et al. (2019). Numerical assessment of failure potential of a large mine waste dump in Panzhihua City, China. Eng. Geol. 253, 171-183. doi:10.1016/j.enggeo.2019.03.002

Chen, J., Yao, J., Mao, Z., Li, Q., Luo, A., Deng, X., et al. (2019a). Sedimentary and diagenetic controls on reservoir quality of low-porosity and low-permeability sandstone reservoirs in chang101, upper triassic yanchang formation in the Shanbei area, Ordos Basin, China. Mar. Petrol. Geol. 105, 204-221. doi:10.1016/ j.marpetgeo.2019.04.027

Chen, R.-P., Liu, P., Liu, X.-M., Wang, P.-F., and Kang, X. (2019b). Pore-scale model for estimating the bimodal soil-water characteristic curve and hydraulic the weight will increase, effective pressure will also increase, and, with water taking a long time to flow throughout the waste dump soil, slope friction will decrease, resulting in a landslide.

(2) The effective pressure directly influences the void ratio, porosity, and coefficient of permeability of the soil.

(3) Coarse specimen volume decreases dramatically with the increase in effective pressure. However, the values of the void ratio, porosity, and the coefficient of permeability continue to be high. When effective pressure on other specimens is applied, void ratio, porosity, and coefficient of permeability values became low, but for coarse specimens, values are high.

(4) The increase in the effective pressure increases coarse specimen breakage. Coarse specimen breakage creates strong movements in the waste dump, leading to a decrease in the stability $(F s)$ and causing a landslide.

These significant results found indicate that further studies should be conducted about porosity, void ratio, coefficient of permeability, and effective pressure variations. Based on the results found, future researches can deeply study the coarse specimen variations, layer organization, and slope compositions as one of the significant future research topics for better and safer waste dump environments and working conditions.

\section{DATA AVAILABILITY STATEMENT}

The raw data supporting the conclusions of this article will be made available by the authors, without undue reservation.

\section{AUTHOR CONTRIBUTIONS}

All authors listed have made a substantial, direct, and intellectual contribution to the work and approved it for publication.

\section{ACKNOWLEDGMENTS}

This work was financially supported by the National Natural Science Foundation of China (51774271); National Natural Science Foundation of China (51804298). conductivity of compacted soils with different initial densities. Eng. Geol. 260, 105199. doi:10.1016/j.enggeo.2019.105199

Chen, S.-K., He, Q.-D., Cao, J.-G., and Cae, J. G. (2018). Seepage simulation of high concrete-faced rockfill dams based on generalized equivalent continuum model. Water Sci. Eng. 11 (3), 250-257. doi:10.1016/j.wse.2018.10.004

Chen, Y., Withanage, K. R., Uchimura, T., Mao, W., and Nie, W. (2020). Shear deformation and failure of unsaturated sandy soils in surface layers of slopes during rainwater infiltration. Measurement 149, 107001. doi:10.1016/j.measurement.2019.107001

Cheng, W. J., Nan, G. X., and Guo, M. S. (2014). Effects of pore-water pressure distribution on slope stability under rainfall infiltration. EJGE 19, 436-480.

Damiano, E., Greco, R., Guida, A., Olivares, L., and Picarelli, L. (2017). Investigation on rainwater infiltration into layered shallow covers in pyroclastic soils and its effect on slope stability. Eng. Geol. 220, 208-218. doi:10.1016/j.enggeo.2017.02.006 
Das, B. M., and Sobhan, K. (2016). Soil mechanics Edn. 8. 132. Pequim, China: China Machine Press, 436-480.

Guan, G. S., Rahardjo, H., and Choon, L. E. (2010). Shear strength equations for unsaturated soil under drying and wetting. J. Geotech. Geoenviron. Eng. 136 (4), 594-606. doi:10.1061/(ASCE)GT.1943-5606.0000261

Gui, M.-W., and Wu, Y.-M. (2014). Failure of soil under water infiltration condition. Eng. Geol. 181, 124-141. doi:10.1016/j.enggeo.2014.07.005

Han, L., Zhou, W., Cai, Q.-X., Shu, J.-S., Jing, H.-W., and Li, X.(2015). Experimental study on remodeling strength of granular materials under different loads and lengths of time. J. Cent. South Univ. 22, 2783-2790. doi:10.1007/s11771-015-2809-y

Hou, X., Vanapalli, S. K., and Li, T. (2018). Water infiltration characteristics in loess associated with irrigation activities and its influence on the slope stability in Heifangtai loess highland, China. Eng. Geol. 234, 27-37. doi:10.1016/j. enggeo.2017.12.020

Kainthola, A., Verma, D., Gupte, S. S., and Singh, T. N. (2011). A coal mine dump stability analysis-A case study. Gm 01, 1-13. doi:10.4236/gm.2011.11001

Kim, Y., Rahardjo, H., and Satyanaga, A. (2018). Numerical simulations of triaxial shearing-infiltration tests. Soils Found. 58, 398-411. doi:10.1016/j.sandf.2018.02.009

Liu, Q. Q., and Li, J. C. (2015). Effects of water seepage on the stability of soilslopes. Procedia. IUTAM. 17, 29-39. doi:10.1016/j.piutam.2015.06.006

Mohammadshirazi, F., McLaughlin, R. A., Heitman, J. L., and Brown, V. K. (2017). A multi-year study of tillage and amendment effects on compacted soils. J. Environ. Manag. 203, 533-541. doi:10.1016/j.jenvman.2017.07.031

Oh, W. T., and Vanapalli, S. K. (2010). Influence of rain infiltration on the stability of compacted soil slopes. Comput. Geotech. 37, 649-657. doi:10.1016/j. compgeo.2010.04.003

Rahmouni, A., Boukalouch, M., Boulanouar, A., Samaouali, A., Géraud, Y., and Sebbani, J. (2013). Permeability and porosity of rocks and their relationship based onlaboratory measurements. J. Civil Environ. Res. 5, 8. doi:10.4236/ijg. 2013.49124not

Rahmouni, A., Boulanouar, A., Boukalouch, M., Géraud, Y., Samaouali, A., Harnafi, M., et al. (2014). Relationships between porosity and permeability of calcarenite rocksbased on laboratory measurements. J. Mater. Environ. Sci. 5 (3), 931-936. doi:10.1007/s12517-012-0760-x

Rosli, R. N., Selamat, M. R., and Ramli, M. H. (2019). Shear strength and permeability properties of lateritic soils from North West Malaysia due to extended compaction. Mater. Today. 17, 630-639. doi:10.1016/j.matpr.2019.06.344
Shakesby, R. A., and Whitlow, J. R. (1991). Failure of a mine waste dump in Zimbabwe: causes and consequences. Environ. Geol. Water Sci. 18, 143-153. doi:10.1007/BF01704668

Sharma, R., Rai, R., and Shrivastva, B. K. (2017). Dump slope rating for Indian coal mining. Res. J. Min. 1 (1), 12-26. doi:10.1007/s12594-016-0540-4

Tan, G., and Chen, Y. (2016). Experimental study of cohesive sediment consolidation and its effect on seepage from dam foundations. Int. J. Sediment Res. 31, 53-60. doi:10.1016/j.ijsrc.2015.08.001

Tavakoli Dastjerdi, M. H., Habibagahi, G., and Nikooee, E. (2014). Effect of confining stress on soil water retention curve and its impact on the shear strength of unsaturated soils. Vadose Zone J. 13 (5), 1-11. doi:10.2136/vzj2013. 05.0094

Verma, D., Kainthola, A., Gupte, S. S., and Singh, T. N. (2013). A finite element approach of stability analysis of internal dump slope in wardha valley coal field, India, Maharashtra. Am. J. Min. Metal. 1 (No. 1), 1-6. doi:10.12691/ajmm-1-1-1

Wen, B.-P., and Yan, Y.-J. (2014). Influence of structure on shear characteristics of the unsaturated loess in Lanzhou, China. Eng. Geol. 168, 46-58. doi:10.1016/j. enggeo.2013.10.023

Zhang, F., Wang, G., Kamai, T., and Chen, W. (2014). Effect of pore-water chemistry on undrained shear behaviour of saturated loess. Q. J. Eng. Geol. Hydrogeol. 47, 201-210. doi:10.1144/qjegh2013-085

Zhang, F., Wang, G., Kamai, T., Chen, W., Zhang, D., and Yang, J. (2013). Undrained shear behavior of loess saturated with different concentrations of sodium chloride solution. Eng. Geol. 155, 69-79. doi:10.1016/j.enggeo.2012.12.018

Zhou, Y. F., Tham, L. G., Yan, R. W. M., and Xu, L. (2014). The mechanism of soil failures along cracks subjected to water infiltration. Comput. Geotech. 55, 330-341. doi:10.1016/j.compgeo.2013.09.009

Conflict of Interest: The authors declare that the research was conducted in the absence of any commercial or financial relationships that could be construed as a potential conflict of interest.

Copyright $\odot 2021$ Tovele, Han and Shu. This is an open-access article distributed under the terms of the Creative Commons Attribution License (CC BY). The use, distribution or reproduction in other forums is permitted, provided the original author(s) and the copyright owner(s) are credited and that the original publication in this journal is cited, in accordance with accepted academic practice. No use, distribution or reproduction is permitted which does not comply with these terms. 